\title{
Analysis of Inhibitor Film Coated on Nickel
}

\author{
Kiyoshi SAKURAI $^{\mathrm{a},{ }^{*}}$ and Tsugito YAMASHITA ${ }^{\mathrm{b}}$
}

\begin{abstract}
${ }^{a}$ Graduate School of Engineering, Kanto Gakuin University(1-50-1, Mutsuurahigashi, Kanazawa-ku, Yokohama-shi, Kanagawa 236-8501)
${ }^{\mathrm{b}}$ Faculty of Engineering, Kanto Gakuin University(1-50-1, Mutsuurahigashi, Kanazawa-ku, Yokohama-shi, Kanagawa 236-8501)
\end{abstract}

\section{Introduction}

Gold plated films are used in switches and connectors in the electronics industry due to high stability and high conductivity, for which nickel plated film is used as an undercoat. Recently, a demand for plating of thinner gold plated films has materialized as to reduce the use of the expensive metal, however, thinning the gold plated film results in corrosion causing pinholes. The mechanism of the corrosion generally involves formation of a local electrolytic cell between the gold plated film and the nickel plated undercoat. A post-treatment has been incorporated to inhibit corrosion and discoloration after gold plating process where rust is prevented by an inhibitor-effect. Although inhibitive effects by organic films on copper, silver, iron, and alloys have been reported ${ }^{1) \sim 4)}$, similar investigations and surface analyses of nickel are scarce. We have however shown inhibitive-effects of films of benzothiazole compounds on nickel ${ }^{5), 6}$, where benzothiazole compounds out performed urea followed by thiazole compounds which also displayed anti-corrosion characteristics. In this study, nickel substrates treated with benzothiazole compounds were analyzed by XPS and DFM and the growth process of inhibitor coated nickel substrates and aspects of corrosion resistance were investigated.

\section{Experimental}

In order to eliminate factors arising from impurities and characteristic structural features inherent to nickel plated films, pure nickel substrates (purity : 99.99\%) were used as working electrodes. Before the treatment process, nickel substrates were degreased with alkali prior to an acid treatment. The alkali degreasing solution consisted of $10 \mathrm{wt} \%$ sodium hydroxide, $35 \mathrm{wt} \%$ sodium carbonate and $25 \mathrm{wt} \%$ sodium silicate and the acid solution $15 \mathrm{wt} \%$ hydrochloric acid.

The nickel substrates were then treated for $1-5 \mathrm{~min}$ at a current density of $0.1 \mathrm{~mA} / \mathrm{cm}^{2}$ in a $0.01 \mathrm{~mol} / \mathrm{dm}^{3}$ inhibitor bath at $323 \mathrm{~K}$. Inhibitors investigated were Benzothiazole (A1), 2-mercaptobenzothiazole (A2), and 2-methylbenzothiazole (A3), shown Fig. 1.

The interface of inhibitor coated nickel substrates were analyzed by XPS (X-ray Photoelectron Spectroscopy) and the surface of the inhibitor coated nickel substrates by DFM (Dynamic Force Microscope).

\section{Results and Discussion}

\subsection{Analysis of inhibitor coated nickel substrates by XPS}

Nickel substrates treated for $1 \mathrm{~min}$. with the inhibitor (A1-3) baths were analyzed by XPS. The resulting spectra are shown in Fig. 2. No peak in the $S 2 p$ spectrum of the untreated nickel substrate could be observed contrary to the Benzothiazole and 2-mercaptobenzothiazole coated nickel substrates for which peaks at 162 and $164 \mathrm{eV}$ corresponded to (-SH, -S-Ni-S-) and (-S-S-, -C-S$\mathrm{C}-)$ respectively appeared. The peak at $168 \mathrm{eV}$ was considered to result from (-C-S-C-) because this bonding system was common to all compounds analyzed. Similarly no peak in the N 1s spectrum of the untreated nickel substrate was apparent. Accordingly, peaks at $399(-\mathrm{C}=\mathrm{N}-)$ and $400 \mathrm{eV}(-\mathrm{C}-\mathrm{N}-\mathrm{Ni}-)$ from the inhibitors

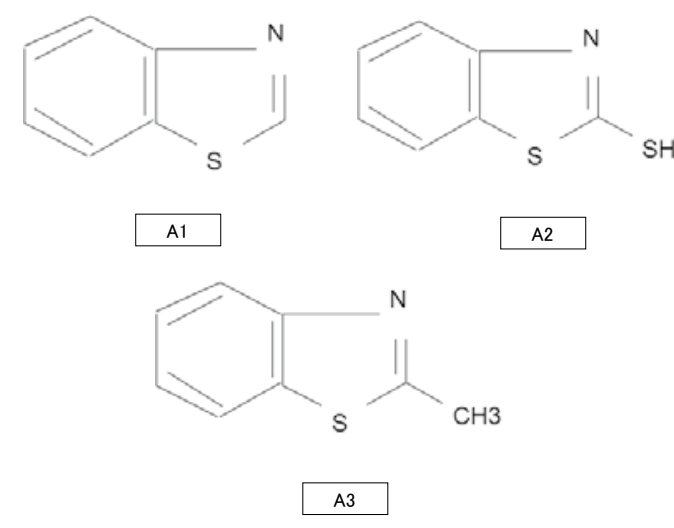

Fig. 1 Benzothiazole compounds.
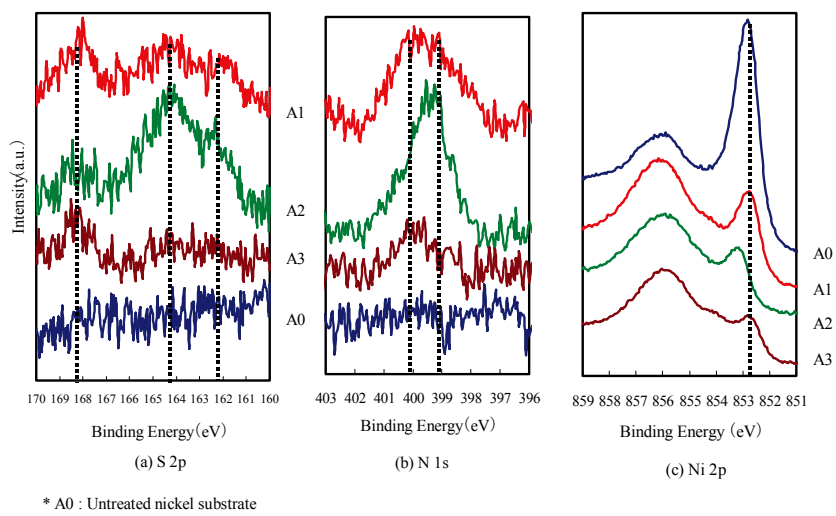

Fig. 2 XPS spectrum of inhibitor on nickel substrate. 

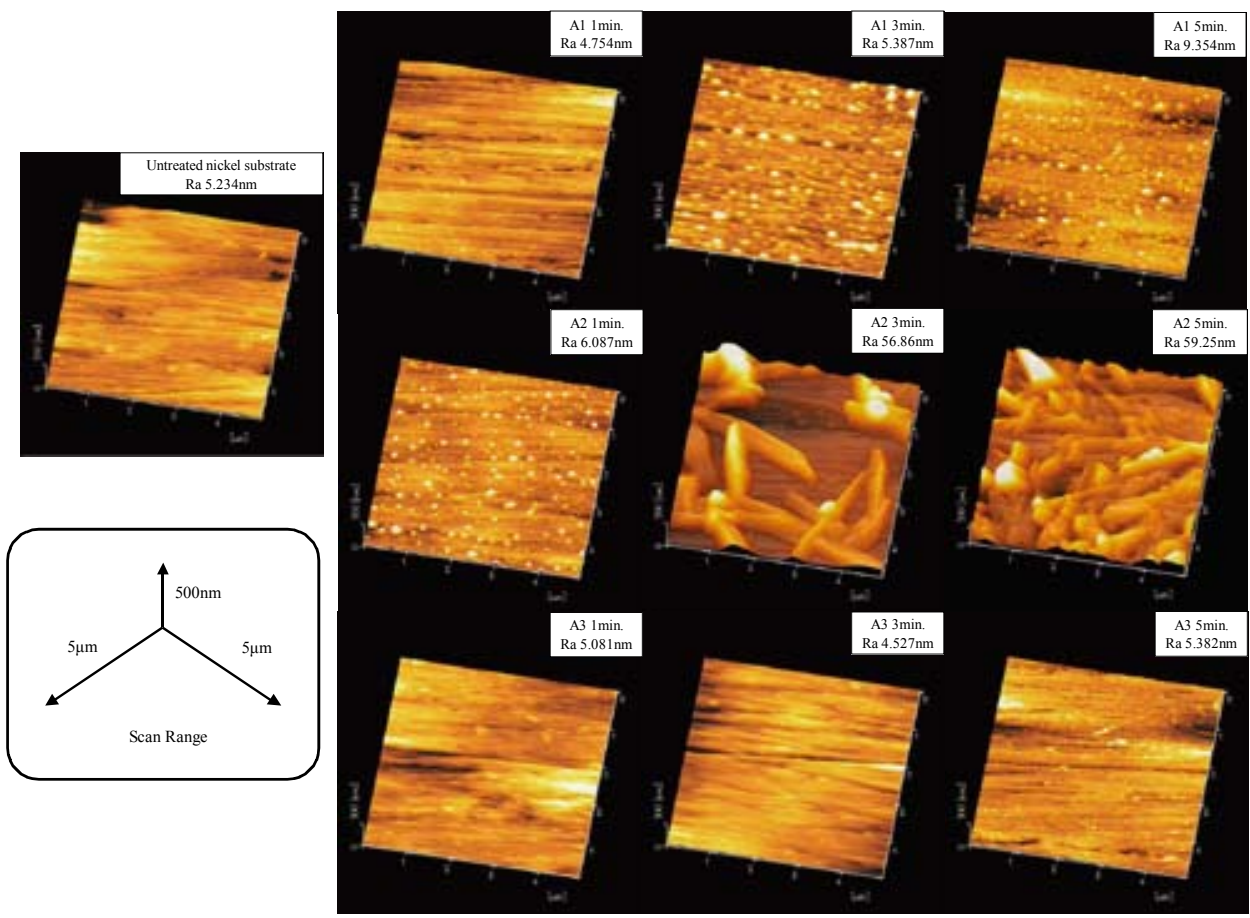

Fig. 3 DFM images of the inhibitor films on nickel substrates.

coated nickel substrates were observed. The $853 \mathrm{eV}\left(\mathrm{Ni}^{0}\right)$ peak in the Ni $2 p$ spectrum of inhibitors coated nickel substrates was less attenuated compared to the untreated nickel substrate, which can be considered a result of the thiazole moiety of the inhibitor bonding to the nickel substrate surface indicating a reaction of benzothiazole compound at the nickel substrate surface.

\section{2 Analysis of inhibitor films by DFM}

The A3 coated nickel substrate appearance was almost unaltered in contrast to that of A1 coated nickel substrate which became slightly yellow in color and A2 coated nickel substrate which was whitened. The color of A2 coated nickel substrate changed for more than $3 \mathrm{~min}$. probably in relation to inhibitor film growth. To further elucidate the growth process of inhibitor films, inhibitors coated nickel substrates were observed by DFM for which resulting images are shown in Fig. 3.

The surface morphology of an A2 film, which required longer deposition time, consisted of like protrusions and had a surface roughness of Ra $60 \mathrm{~nm}$. Slower growing A1 and A3 films on the other hand had only minute features and a surface roughness of less than Ra 10nm, only one sixth of that of the A2 film. In comparison, the surface of an untreated nickel substrate was flat with no protrusions. We speculate that the sulfur or nitrogen are responsible for adsorption onto the nickel substrate, explaining the limited growth of A1 and A3 which have single reaction site. Contrarily, A2 has two reaction sites, which may have enhanced film growth on nickel substrate.

Although growth enhancement of inhibitor film was confirmed for the compound having multiple adsorption sites, in a previous study ${ }^{5), 6)}$ we reported poor corrosion resistance characteristics of the A2 film compared to A1 and A3 films when evaluated by an electrochemical technique. Presumably, exposed $\mathrm{Ni}^{0}$, which has a lower oxidation potential than complexed nickel, areas in the more highly ordered A2 film resulted in inferior corrosion resistance. Therefore, inhibitors with only one adsorption site may be considered superior for corrosion resistance.

\section{Conclusion}

The inhibitor films coated nickel substrates were analyzed by XPS and DFM. It was speculated that the sulfur or nitrogen correlate to the deposition on nickel substrate and that the inhibitor compounds was reacted at the $\mathrm{Ni}^{0}$ surface. Presumably, the A2 film had grown on nickel substrate via two reaction sites resulting in a Ra six timed the roughness of the other two single reaction site inhibitors which comparatively showed limited film growth.

In the case of having multiple adsorption sites, growth of inhibitor film was confirmed but corrosion resistance tended to be inferior, most likely the result of the exposed easily corroded $\mathrm{Ni}^{0}$ regions in the surface structure arising from interference from having two adsorption sites. Based on these results we concluded that single reaction site inhibitors give superior corrosion resistance.

\section{Acknowledgements}

This work was supported by the "High-Tech Research Center" Project by Matching Fund Subsidy for private universities from MEXT (Ministry of Education, Culture, Sports, Science and Technology), 2005-2010.

(Received August 8, 2011 ; Accepted September 11, 2011)

\section{References}

1) T. Notoya, G. W. Poling ; CORRSION, 35, 193 (1979).

2) F. Mansfeld, T. Smith, E. P. Parry ; CORROSION, 27, 289 (1971).

3) N. Dohi, T. Kato, S. Masaki ; Kinzoku Hyomen Gijutsu, 26, 411 (1975).

4)F. B. Growcock, V. R. Lopp, R. J. Josinski ; J. Electrochem. Soc., 135, 823 (1988).

5) K. Sakurai, Y. Urano, T. Yamashita ; 2011 Annual Meeting of the Materials Science Society of Japan, p. 3 (2011).

6) K. Sakurai, T. Yamashita ; Materials Science and Technology, 48, (5) (2011). in print 